\title{
Mendisain GUI Untuk Menampilkan Nilai FFT dan IFFT Menggunakan LabVIEW
}

\author{
Riny Alfina ${ }^{1}$, Indrawan Arifianto ${ }^{1}$, Dwi Astharini ${ }^{1}$, Putri Wulandari ${ }^{1}$
}

\begin{abstract}
Methods FFT (Fast Fourier Transform) is a method for solving discrete signals which method IFFT (Inverse Fast Fourier Transform) is the reciprocal of the FFT method. Basically FFT only used for transformation and must not be separated from the method DFT (Discrete Fourier Transform). DFT is a mathematical transformation method for discrete time signal into a frequency domain. Examples for use of FFT-IFFT such as voice processing, OFDM and others. In this project the author designed the GUI for displaying the FFT and IFFT using LabVIEW. GUI design using Labview will inputed signal infromation or sample as desired and can be changed. From these results we obtained the value of V (amplitude), the value of the frequency and I/O (input/output) can be displayed in a single VI.
\end{abstract}

KEYWORDS: Fast Fourier Transform, Inverse Fast Fourier Transform, LabVIEW, Signal infromation.

ABSTRAK: Metode FFT (Fast Fourier Transform) merupakan metode untuk pemecahan sinyal diskrit yang mana metode IFFT (Inverse Fast Fourier Transform) adalah kebalikan dari metode FFT. Pada dasarnya FFT hanya digunakan untuk melakukan transformasi dan tentunya tidak lepas dari metode DFT (Discrete Fourier Transform). DFT merupakan metode transformasi matematis untuk sinyal waktu diskrit ke dalam domain frekuensi. Contoh untuk penggunaan FFT- IFFT seperti pengolahan suara, OFDM dan lain-lain. Pada projek ini penulis mendisain GUI untuk menampilkan nilai FFT dan IFFT menggunakan LabVIEW. Disain GUI menggunakan LabVIEW ini akan diinput sinyal informasi atau sample sesuai yang diinginkan dan dapat diubah-ubah. Dari hasil tersebut maka didapatkan nilai V (Amplitude), nilai frekuensi dan I/O (Input/Output) dapat ditampilkan dalam satu VI.

KATA KUNCI: Fast Fourier Transform, Inverse Fast Fourier Transform, LabVIEW, Sinyal Informasi.

\section{PENDAHULUAN}

$\mathrm{P}^{\mathrm{s}}$ erkembangan teknologi saat ini merupakan kemajuan teknologi komputer digital dan industry yang cukup pesat. Khususnya bagian pengolahan sinyal digital (Digital Signal Processing). Pengolahan sinyal digital adalah suatu operasi tertentu terhadap suatu sinyal, baik operasi-operasi elementer maupun oeprasi-operasi kompleks dengan teknik digital. FFT adalah suatu algoritma untuk menghitung transformasi Fourier diskrit (Discrete Fourier Transform, DFT) dengan cepat dan efisien. Dan IFFT adalah Inverse atau kebalikan dari FFT yang dapat digunakan untuk menghitung lebih cepat jumlah perkalian kompleks pada perhitungan langsung yaitu $\mathrm{N}^{2}$ menjadi (N/2). Metode IFFT ini akan memberikan perhitungan yang lebih efisien sehingga mempercepat proses sinyal.

Pada tugas projek ini penulis mendisain GUI untuk menampilkan nilai FFT dan IFFT menggunakan LabVIEW. LabVIEW adalah sebuah software pemograman yang diproduksi oleh National Instrument dengan konsep yang berbeda. Seperti bahasa pemograman lainnya yaitu C++, MATLAB atau Visual basic, LabVIEW juga mempunyai fungsi dan peranan yang sama, perbedaannya bahwa LabVIEW menggunakan bahasa pemograman berbasis grafis atau block diagram sementara bahasa pemograman lainnya menggunakan basis text. Dengan spesifikasi menampilkan nilai V (Amplitude), nilai frekuensi, sinyal informasi (sample) dapat diubah-ubah, menampilkan sinyal informasi dan I/O (Input/Output) ditampilkan dalam VI

\section{DASAR TEORI}

\section{SINYAL INFORMASI}

Model system komunikasi (simpli ad) seperti yang terdapat pada skema berikut

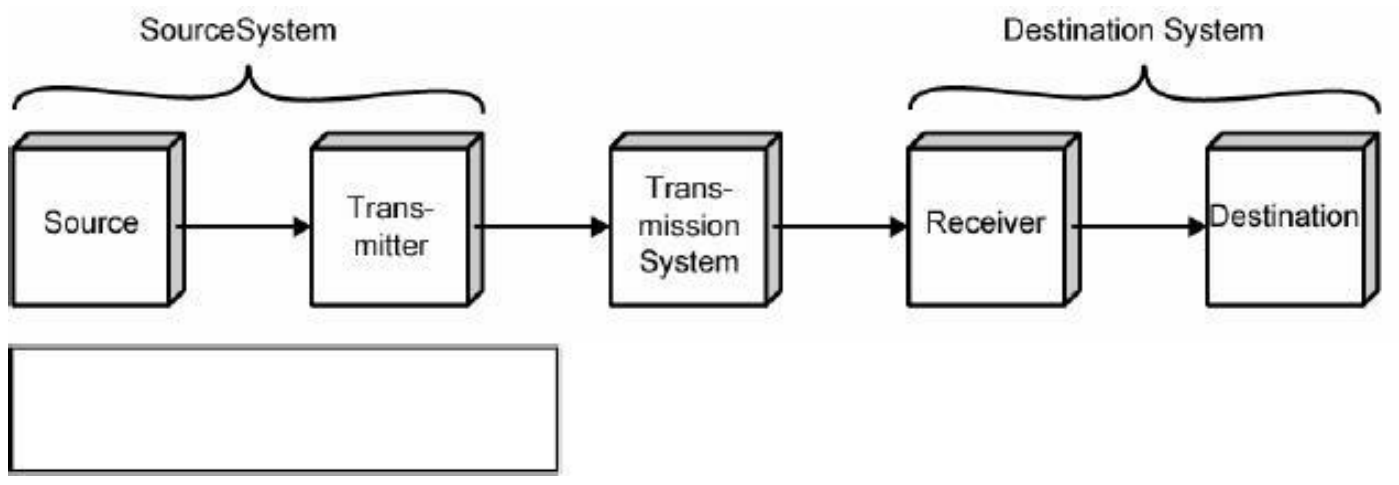

- Gambar 1. Sinyal Informasi

Tugas transmitter adalah mentransfer message ke kanal komunikasi dan mampu mengubah bentuk informasi yang berasal dari manusia/mesin ke dalam sinyal yang cocok (suitable) untukdiangkut medium transmisi. Perpindahan informasi terjadi melalui media transmisi, lalu ada Sumber Informasi yang berupa Data

\footnotetext{
${ }^{1}$ Jurusan Teknik Elektro, Universitas Al Azhar Indonesia
} 
suara(voice) dan Gambar. Setelah itu ada Bentuk Informasi yang berupa Analog \& Suara Manusia dan Digital : data yang berbentuk binary dan yang terakhir yaitu agar informasi dapat berpindah, maka informasi tersebut harus dibuah menjadi sinyal EM.

Sinyal dapat juga diklasifikasikan menjadi beberapa bagian yaituseperti \$erdasarkan \$entuk Sinyal yaitu analog dan digital. Lalu berdasarkan period sinyal yaitu periodik dan aperiodik. Dan yang terakhir berdasarkan komposisi sinyal seperti sinyal sederhana dan sinyal komposit. Suatu gelombang elektromagnetik yang bervariasi secara kontinu dan dapat dipropagasikan melalui berbagai media dengan contoh media: Copper wire media (Twisted pair and coaxial cable) Fiber optic cable, dan Atmosphere or space propagation. Dan Sinyal analog dapat mem-propagasikan data analog maupun digital. Sinyal digital dapat dijelaskan dengan Suatu deretan pulsa-pulsa yang dapat ditransmisikan melalui suatu media seperti diskrit, pulsa tegangan diskontinyu, tiap pulsa adalah satu elemen sinyal, data biner dikodekan ke dalam elemen-elemen sinyal. Dan juga Sinyal digital dapat mem-propagasikan data analog maupun digital. Transmitter akan mengirimkan informasi melalui kanal komunikasi dalam bentuk sinyal elektromagnetik.

Karakteristik gelombang elektromagentik dapat dtinjau melalui konsep time domain maupun konsep frequency domain seperti konsep time domain: meninjau sinyal elektromagnetik dari sisi waktu dan konsep frequency domain: meninjau sinyal elektromagnetik dari sisi frekuensi. Untuk transmisi data, konsep frequency domain jauh lebih penting daripada konsep time domain.

\section{FFT (Fast Fourier Transform)}

Fast Fourier Transform adalah suatu algoritma yang digunakan untuk merepresentasikan

sinyal dalam domain waktu diskrit dan domain frekuensi. Sementara itu, IFFT adalah singkatan dari Inverse Fast Fourier Transform. Membahas mengenai FFT-IFFT tentunya tidak dapat dilepaskan dari DFT (Discrete Fourier Transform). DFT merupakan metode transformasi matematis untuk sinyal waktu diskrit ke dalam domain frekuensi. Secara sederhana dapat dikatakan bahwa DFT merupakan metode transformasi matematis sinyal waktu diskrit, sementara FFT adalah algoritma yang digunakan untuk melakukan transformasi tersebut.

Secara mendasar, masalah komputasional untuk DFT adalah menghitung deret $\mathrm{X}(\mathrm{k})$ dari jumlah bernilai kompleks $\mathrm{N}$ yang diberikan deret data $\mathrm{x}(\mathrm{n})$ lain dengan panjang $\mathrm{N}$, sesuai dengan rumus:

\section{$\left(\rightarrow \quad \sum \quad[\quad]\right.$}

Pada algoritma FFT radiks-2 ada 2 struktur algoritma penting, yaitu algoritma penguraian dalam waktu dan algoritma peguraian dalam frekuensi.

a) Algoritma penguraian dalam waktu.

b) Algoritma penguraian dalam frekuensi.

FFT dipergunakan untuk mengurangi kompleksitas transformasi yang dilakukan dengan DFT. Sebagai perbandingan, bila kita menggunakan DFT, maka kompleksitas transformasi kita adalah sebesar O(N2), sementara dengan menggunakan FFT, selain waktu transformasi yang lebih cepat, kompleksitas transformasi pun menurun, menjadi $\mathrm{O}(\mathrm{N} \log (\mathrm{N}))$. Untuk jumlah sample yang sedikit mungkin perbedaan kompleksitastidak begitu terasa, namun lain ceritanya bila kita mengambil jumlah sample yang sedikit lebih banyak. Misalnya kita hanya mengambil 2 sample, dengan menggunakan DFT, tingkat kompleksitas transformasi kita adalah 4, sementara dengan menggunakan FFT kompleksitasnya sebesar 0,602 .

Perbedaan yang semakin mencolok tampak bila kita mengambil jumlah sample yang lebih banyak lagi, misalnya kita ingin meninjau 64 titik sample, maka kompleksitas dengan menggunakan DFT adalah sebesar 4096, sementara dengan menggunakan FFT kompleksitasnya menjadi 115,6. Perbedaan yang sangat mencolok melihat perbandingan yang mencapai hampir 40 kali lipatnya. Kompleksitas transformasi ini terutama menjadi vital saat diimplementasikan pada perangkat riil. Perbandingan kompleksitas DFT dan FFT dapat dilihat pada gambar berikut: 


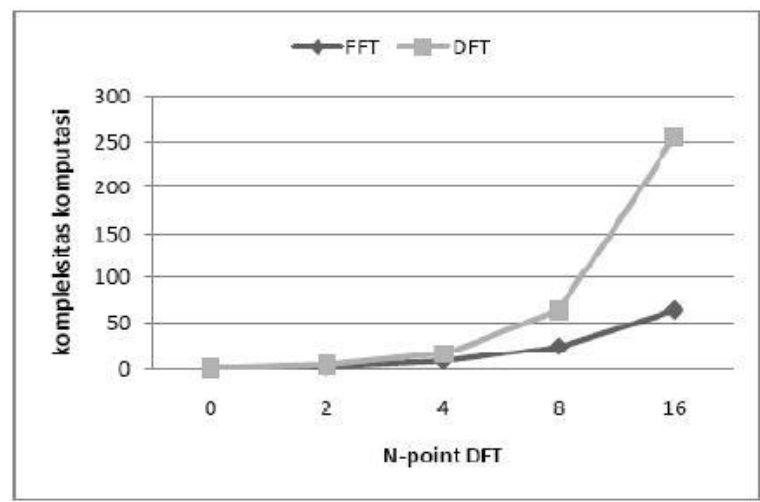

ש Gambar 2. Komplesitas FFT dan DFT

\section{IFFT (Inverse Fast Fourier Transform)}

IFFT (Inverse Fast Fourier Transform) adalah inverse atau kebalikan dari FFT. Sementara itu, IFFT dapat dirumuskan sebagai berikut:

$$
(\rightarrow \quad \Sigma \quad[\text { ] }
$$

\section{LabVIEW}

National Instruments LabVIEW adalah sebuah graphical programming environtment terbuka yang ditetapkan oleh standar industry untuk aplikasi pengujian pengukuran dan otomasi. Sebuah perkembangan pada pemograman grafik dimana teknisi dapat menggunakan untuk mendisain suatu sistem menyerupai bentuk sistem aslinya, dapay melakukan pengamatan dengan hasil yang maksimal dan dapat mengontrol suatu aplikasi dengan programmable autonomation controllers. LabVIEW adalah sebuah sistem pemograman yang terbuka dan fleksibel sehingga teknisi dapat menghubugkannya dengan alat lainnya seperti PLC dan PAC menggunakan paket software

\section{HASIL DAN PEMBAHASAN}

Pada projek LabVIEW ini hasil yang didapatkan denga mengubah sample(sinyal informasi) sebagai berikut:

Sinyal Informasi $50 \mathrm{~Hz}$

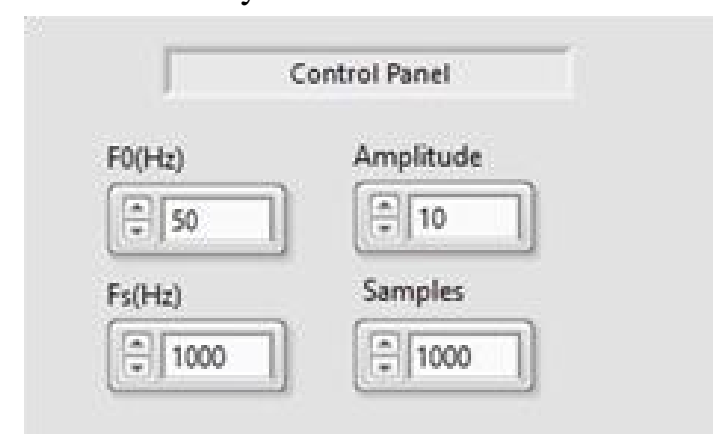

שambar 3. Sinyal Informasi $50 \mathrm{~Hz}$ 


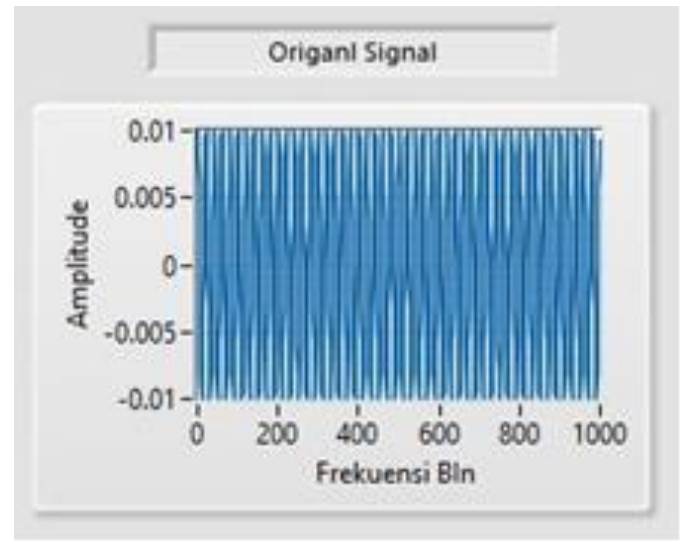

- Gambar 4. Sinyal Original $50 \mathrm{~Hz}$

Pada gambar 1 dijelaskan bahwa F0 $(\mathrm{Hz})=50 \mathrm{~Hz}, \mathrm{Fs}(\mathrm{Hz})=1000$, Amplitude $=10$ dan samples $=10000$. Ketika F0(Hz) bernilai $50 \mathrm{~Hz}$ maka hasil output sinyalnya adalah sebagai berikut:

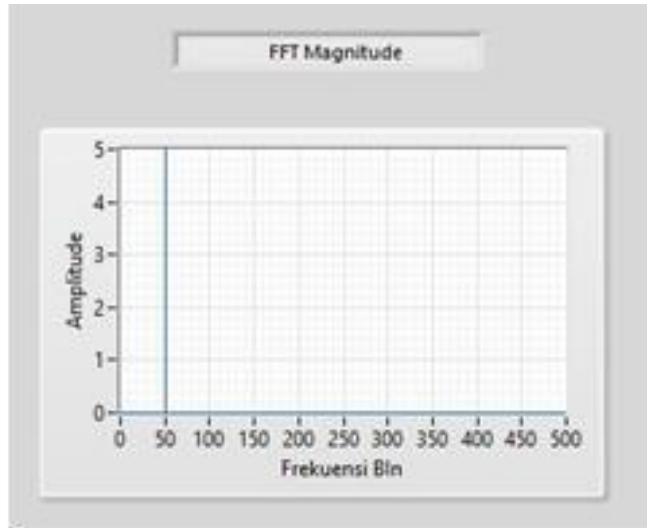

- Gambar 5. Keluaran Magnitude Sinyal FFT $50 \mathrm{~Hz}$

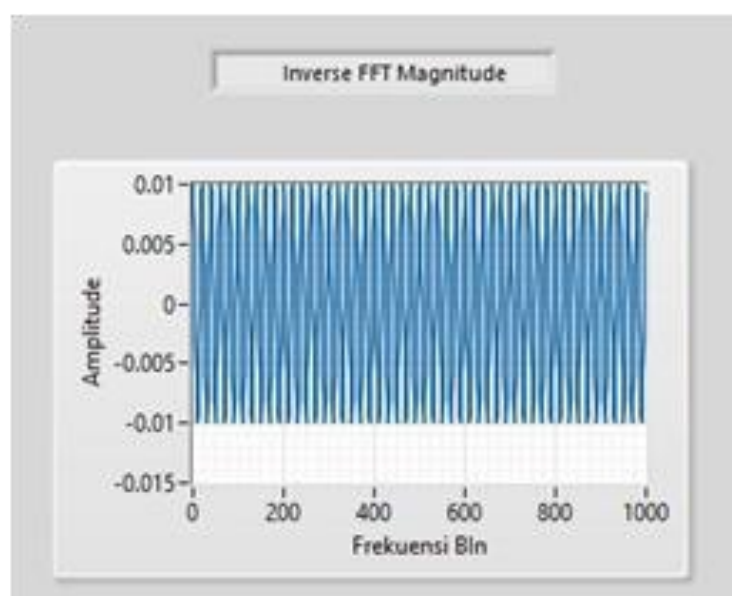

— Gambar 6. Keluaran Magnitude Sinyal IFFT $50 \mathrm{~Hz}$

Dari hasil gambar dilihat bhawa dengan input frekuensi $50 \mathrm{~Hz}$ maka pada gambar 3 terlihat amplitude amksimum pada $50 \mathrm{~Hz}$, dan dari gambar 4 terlihat bahwa hasil invers FFT sesuai dengan sinyal asli.

Sinyal Informasi $100 \mathrm{~Hz}$ 


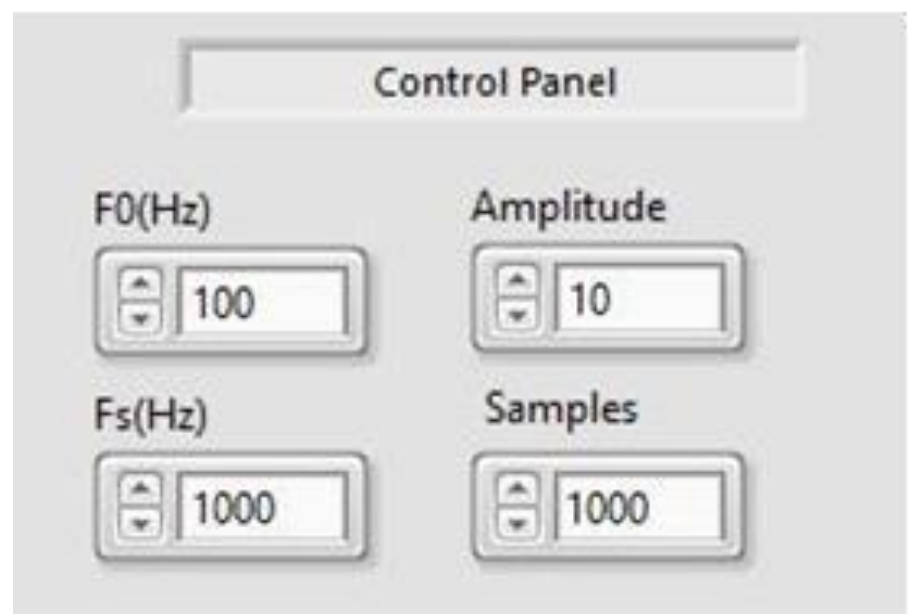

- Gambar 7. Sinyal Informasi $100 \mathrm{~Hz}$

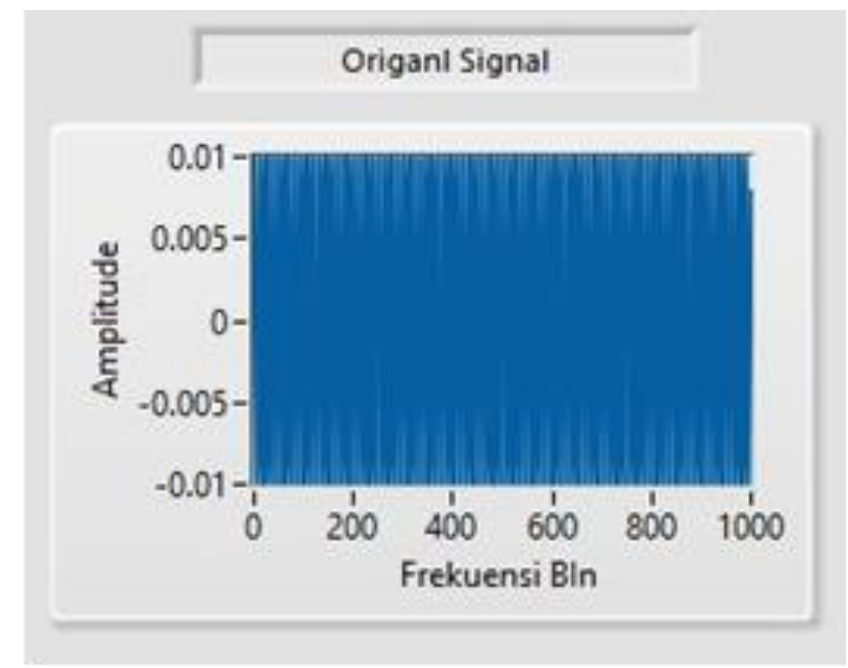

- Gambar 8. Sinyal Original $100 \mathrm{~Hz}$

Pada gambar 5 dijelaskan bahwa F0(Hz) $=100 \mathrm{~Hz}, \mathrm{Fs}(\mathrm{Hz})=1000$, Amplitude $=10$ dan samples $=$ 10000. Ketika F0(Hz) bernilai $100 \mathrm{~Hz}$ maka hasil output sinyalnya adalah sebagai berikut.

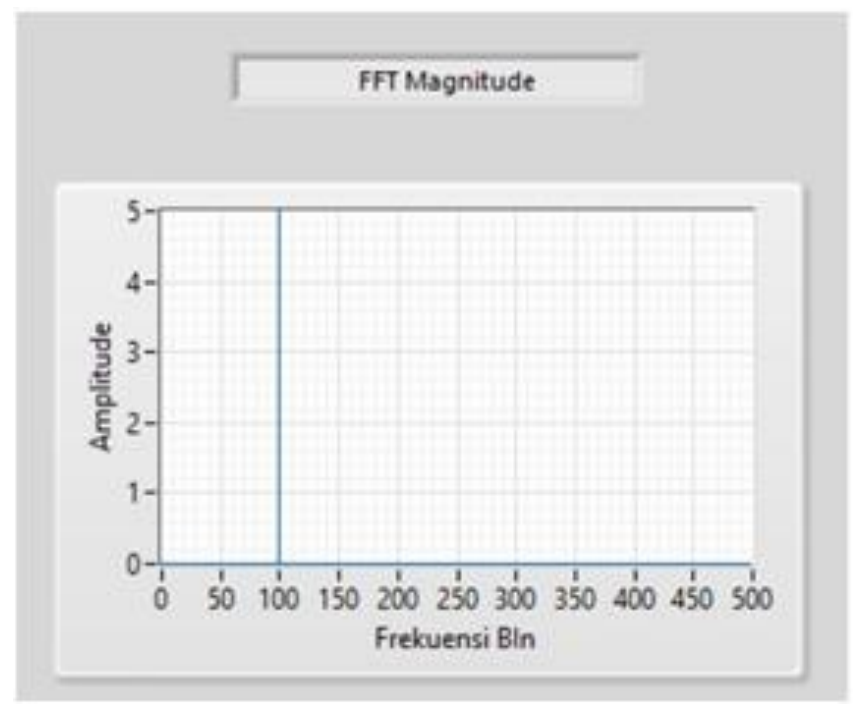

- Gambar 9. Keluaran Magnitude Sinyal FFT $100 \mathrm{~Hz}$

Dari hasil gambar dilihat bahwa dengan input frekuensi $100 \mathrm{~Hz}$ maka pada gambar 7 terlihat bahwa amplitude maksimum pada $100 \mathrm{~Hz}$, dan dari gambar 8 terlihat bahwa hasil invers FFT sesuai dengan sinyal aslinya Sinyal Informasi $150 \mathrm{~Hz}$ 


\section{Control Panel}

$\mathrm{FO}(\mathrm{Hz})$

150

$\mathrm{Fs}(\mathrm{Hz})$

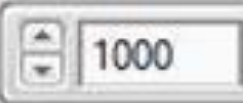

Amplitude

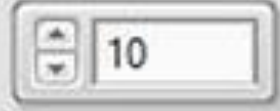

Samples

1000

- Gambar 11. Sinyal Infromasi $150 \mathrm{~Hz}$

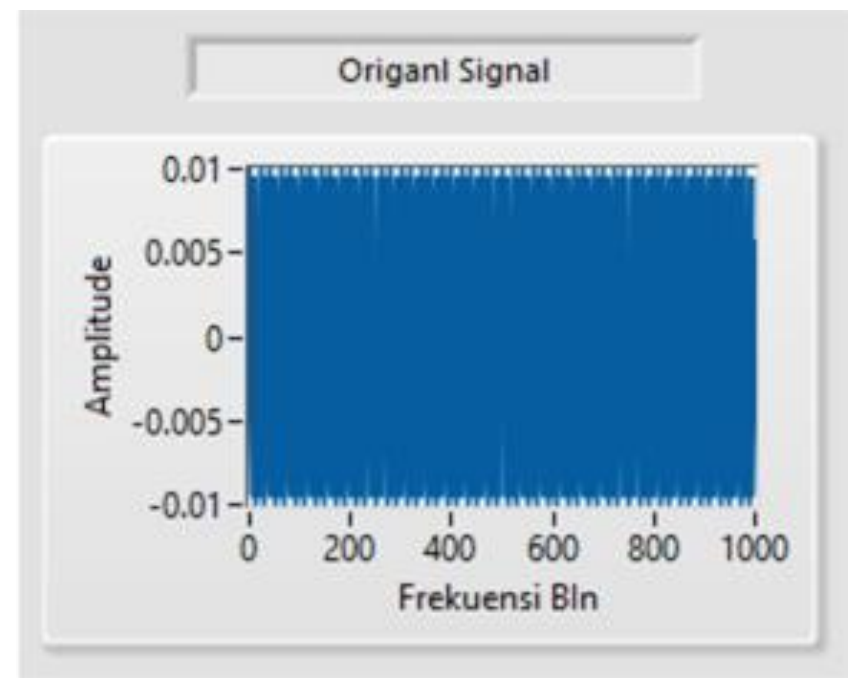

- Gambar 12. Sinyal Original $150 \mathrm{~Hz}$

Pada gambar 10 dijelaskan bahwa $\mathrm{F} 0(\mathrm{~Hz})=150 \mathrm{~Hz}, \mathrm{Fz}(\mathrm{Hz})=1000$, Amplitude $=10$ dan samples $=10000$. Ketika F0(Hz) bernilai $150 \mathrm{~Hz}$ maka hasil keluaran sinyalnya adalah sebagai berikut:

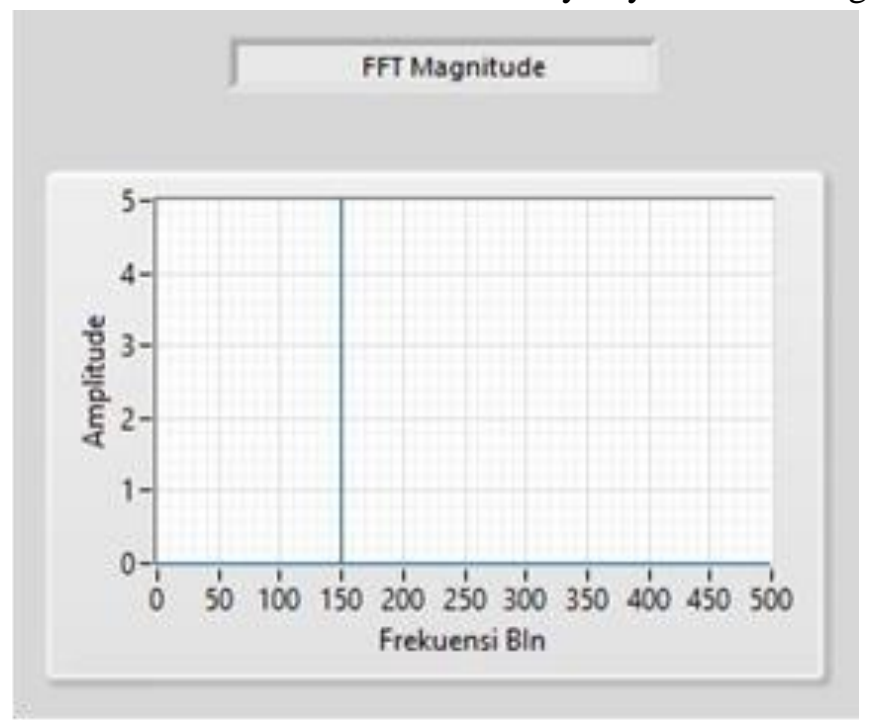

- Gambar 13. Keluaran Magnitude Sinyal FFT $150 \mathrm{~Hz}$ 


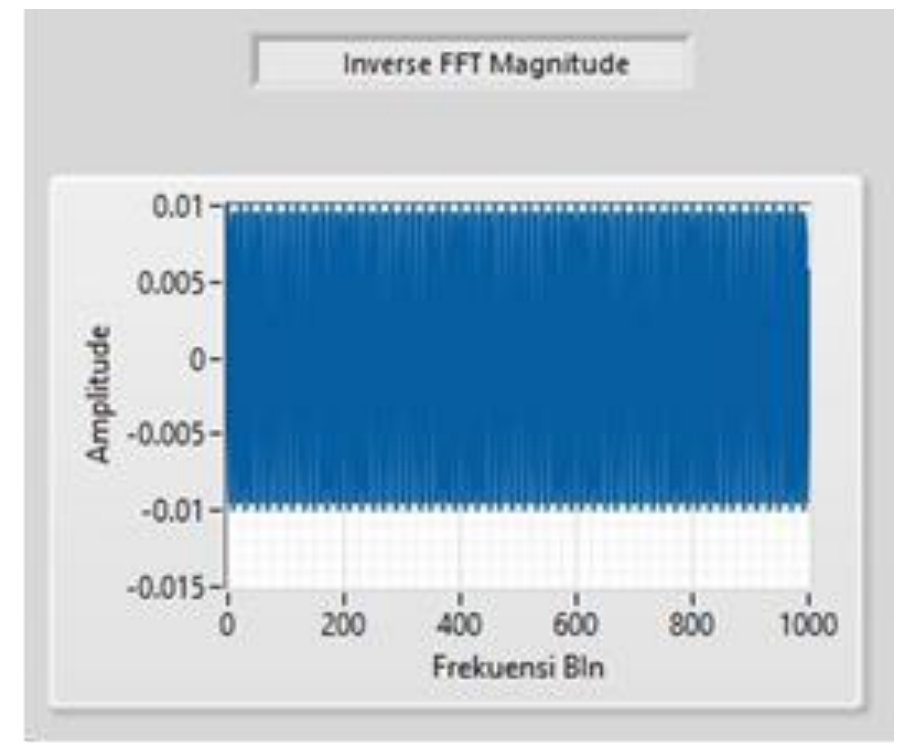

- Gambar 14. Keluaran Magnitude Sinyal IFFT $150 \mathrm{~Hz}$

Dari hasil gambar dilihat bahwa dengan input frekuensi $150 \mathrm{~Hz}$ maka gambar 11 terlihat bahwa amplitude maksimum pada $150 \mathrm{~Hz}$, dan dari gambar 12 terlihat bahwa hasil invers FFT sesuai dengan sinyal asli.

\section{KESIMPULAN}

Dari hasil diatas dapat disimpulkan bahwa penggunaan LabVIEW akan memudahkan dalam proses pengolahan sinyal, dan pada paper ini yaitu untuk mengubah sinyal dalam bentuk FFT dan IFFT.

\section{DAFTAR PUSTAKA}

[1]. Docplayer.info.’Bab II DASAR TEORI LabVIEW", 2018.

Internet : https://docplayer.info/40736952-Bab-ii-dasar-teori-labview-adalah-sebuah- softwarepemograman-yang-diproduksi-oleh.html . [ 30 Nov 2018 ]

[2].Academia.'Implementasi Algoritma FFT (Fast Fourier Transform) Pada Digital Signal Processing (DSP) TMS320C542", 2018.

Internet:http://www.academia.edu/23253769/Implementasi Algoritma FFT Fast Fourier

Transform_Pada_Digital_Signal_Processor_DSP_TMS320C542 . [ 30 Nov 2018 ]

[3].Deetoo88."'Mengenal FFT-IFFT", 2018.

Internet: https://deeto88.wordpress.com/2010/09/28/mengenal-fft-ifft/ . [ 30 Nov 2018 ]

[4]. Scribd."Sinyal Infromasi”, 2018

.Internet: https://www.scribd.com/document/347577993/sinyal-informasi . [

30 Nov 2018 ] 